NASA/TM-2009-215632

AIAA-2009-1073

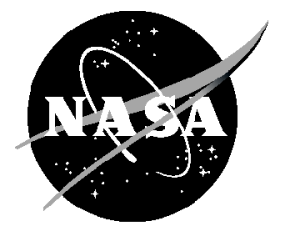

\title{
An Experimental Evaluation of the Performance of Two Combination Pitot Pressure Probes
}

David J. Arend and John D. Saunders

Glenn Research Center, Cleveland, Ohio 


\section{NASA STI Program . . . in Profile}

Since its founding, NASA has been dedicated to the advancement of aeronautics and space science. The NASA Scientific and Technical Information (STI) program plays a key part in helping NASA maintain this important role.

The NASA STI Program operates under the auspices of the Agency Chief Information Officer. It collects, organizes, provides for archiving, and disseminates NASA's STI. The NASA STI program provides access to the NASA Aeronautics and Space Database and its public interface, the NASA Technical Reports Server, thus providing one of the largest collections of aeronautical and space science STI in the world. Results are published in both non-NASA channels and by NASA in the NASA STI Report Series, which includes the following report types:

- TECHNICAL PUBLICATION. Reports of completed research or a major significant phase of research that present the results of NASA programs and include extensive data or theoretical analysis. Includes compilations of significant scientific and technical data and information deemed to be of continuing reference value. NASA counterpart of peer-reviewed formal professional papers but has less stringent limitations on manuscript length and extent of graphic presentations.

- TECHNICAL MEMORANDUM. Scientific and technical findings that are preliminary or of specialized interest, e.g., quick release reports, working papers, and bibliographies that contain minimal annotation. Does not contain extensive analysis.

- CONTRACTOR REPORT. Scientific and technical findings by NASA-sponsored contractors and grantees.

- CONFERENCE PUBLICATION. Collected papers from scientific and technical conferences, symposia, seminars, or other meetings sponsored or cosponsored by NASA.

- SPECIAL PUBLICATION. Scientific, technical, or historical information from NASA programs, projects, and missions, often concerned with subjects having substantial public interest.

- TECHNICAL TRANSLATION. Englishlanguage translations of foreign scientific and technical material pertinent to NASA's mission.

Specialized services also include creating custom thesauri, building customized databases, organizing and publishing research results.

For more information about the NASA STI program, see the following:

- Access the NASA STI program home page at http://www.sti.nasa.gov

- E-mail your question via the Internet to help@ sti.nasa.gov

- Fax your question to the NASA STI Help Desk at $443-757-5803$

- Telephone the NASA STI Help Desk at 443-757-5802

- Write to: NASA Center for AeroSpace Information (CASI) 7115 Standard Drive Hanover, MD 21076-1320 


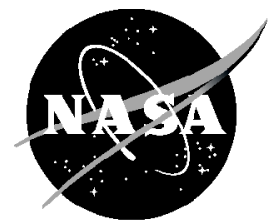

\section{An Experimental Evaluation of the Performance of Two Combination Pitot Pressure Probes}

David J. Arend and John D. Saunders

Glenn Research Center, Cleveland, Ohio

Prepared for the

47th Aerospace Sciences Meeting

sponsored by the American Institute of Aeronautics and Astronautics

Orlando, Florida, January 5-8, 2009

National Aeronautics and

Space Administration

Glenn Research Center Cleveland, Ohio 44135 


\section{Acknowledgments}

The authors gratefully acknowledge Jose Gonsalez who managed, engineered and operated the probe calibration laboratory used for this work. His dedication, attention to detail and help in setting up and conducting these tests greatly contributed to the quality of this work.

Trade names and trademarks are used in this report for identification only. Their usage does not constitute an official endorsement, either expressed or implied, by the National Aeronautics and Space Administration.

This work was sponsored by the Fundamental Aeronautics Program at the NASA Glenn Research Center.

Level of Review: This material has been technically reviewed by technical management.

Available from

NASA Center for Aerospace Information 7115 Standard Drive

Hanover, MD 21076-1320
National Technical Information Service 5285 Port Royal Road Springfield, VA 22161

Available electronically at http://gltrs.grc.nasa.gov 


\title{
An Experimental Evaluation of the Performance of Two Combination Pitot Pressure Probes
}

\author{
David J. Arend and John D. Saunders \\ National Aeronautics and Space Administration \\ Glenn Research Center \\ Cleveland, Ohio 44135
}

\begin{abstract}
Experimental tests have been completed which recorded the ability of two combination steady state and high response time varying Pitot probe designs to accurately measure steady stagnation pressure at a single location in a flow field. Tests were conducted of double-barreled and coannular Prati probes in a 3.5 in. diameter free jet probe calibration facility from Mach 0.1 to 0.9. Geometric symmetry and pitch $\left(-40^{\circ}\right.$ to $\left.40^{\circ}\right)$ and yaw $\left(0^{\circ}\right.$ to $\left.40^{\circ}\right)$ angle actuation were used to fully evaluate the probes. These tests revealed that the double-barreled configuration induced error in its steady state measurement at zero incidence that increased consistently with jet Mach number to 1.1 percent at Mach 0.9 . For all Mach numbers, the double-barreled probe nulled at a pitch angle of approximately $7.0^{\circ}$ and provided inconsistent measurements when yawed. The double-barreled probe provided adequate measurements via both its steady state and high response tubes (within \pm 0.15 percent accuracy) over unacceptable ranges of biased pitch and inconsistent yaw angles which varied with Mach number. By comparison, the coannular probe provided accurate measurements (at zero incidence) for all jet Mach numbers as well as over a flow angularity range which varied from $\pm 26.0^{\circ}$ at Mach 0.3 to $\pm 14.0^{\circ}$ at Mach 0.9 . Based on these results, the Prati probe is established as the preferred design. Further experimental tests are recommended to document the frequency response characteristics of the Prati probe.
\end{abstract}

\section{Nomenclature}

\begin{tabular}{|c|c|}
\hline $\mathbf{M}$ & Mach number \\
\hline $\mathbf{P}$ & total pressure, psia \\
\hline$x$ & axial coordinate (origin located at the center of the free jet nozzle exit), inches \\
\hline$y$ & horizontal coordinate (perpendicular to free jet axis), inches \\
\hline$z$ & vertical coordinate (perpendicular to free jet axis), inches \\
\hline$\alpha$ & pitch angle, degrees \\
\hline$\beta$ & yaw angle, degrees \\
\hline $\begin{array}{l}\text { Subscripts } \\
\text { jet } \\
\text { plenum } \\
\text { t }\end{array}$ & $\begin{array}{l}\text { pertaining to Pitot probe measurements } \\
\text { pertaining to CE-12 plenum chamber, equivalent to station } 1 \\
\text { total or stagnation conditions }\end{array}$ \\
\hline
\end{tabular}

\section{Introduction}

Among its responsibilities, the National Aeronautics and Space Administration (NASA) is tasked with conducting aeronautics research and ensuring the widest practical dissemination of the results obtained. This necessarily includes air breathing propulsion systems, inlets, supporting and related technologies including instrumentation. One such development in need of attention is the use of double-barreled type combination Pitot pressure probes and the effect this practice can have on experimental test results so obtained. More specifically, the inaccuracy of this probe type became known through the completion of a series of ancillary instrumentation tests in support of a larger wind tunnel test program. The purpose of this paper is to 
formally document these test results for the wider experimental research community and to provide an alternative configuration which NASA has successfully utilized for many years.

Pitot probes have been used for many decades to obtain measurements of the stagnation pressure within a fluid stream. However, their use for obtaining both its steady state and time varying (high response) components presents complications. The current practical inability of highly accurate pressure transducers to acquire data over a sufficient bandwidth of frequencies combined with the inability of high response transducers to measure pressure with sufficient accuracy and calibration stability have necessitated a compromise approach. In order to satisfy research requirements, both must often be utilized. To do so, combination Pitot pressure probes of various configurations have been designed which record simultaneous measurements at the same or very nearly the same flow field location. Depending upon the characteristics of the flow field being measured, these two measurements can be combined to provide more accurate, high response stagnation pressure data.

Obtaining accurate measurements of stagnation pressure is particularly important for inlet research. Total pressure recovery - computed from the measured stagnation pressure at a location in a flow and the free stream total pressure - is a key performance parameter. Subsonic Blended Wing Body (BWB) aircraft systems studies have determined that for an engine with a bypass ratio of 10 fed by a boundary layer ingesting inlet, each 1 percent loss in total pressure recovery results in a 1.9 percent loss in net thrust (Ref. 1). Accurate Pitot pressure measurements are also critically important for assessing and mitigating inlet distortion in such systems. For a supersonic High Speed Civil Transport (HSCT), each 1 percent reduction in total pressure recovery can reduce the net thrust of the engine by 1.4 percent and increase the aircraft design's Maximum Take-Off Weight (MTOW) by nearly 5,000 lb (Ref. 2). Given the importance of inlet total pressure recovery to an aircraft's performance, its value needs to be measured accurately. A typical requirement is that total pressure recovery measurements be made accurate to within \pm 0.1 percent.

The present work addresses two such probe configurations which are used to make these measurements. The first is known as a double-barreled or "shotgun" probe. This probe configuration utilizes two separate Pitot configured ports that are located immediately adjacent to - in fact, touchingone another. Use of the double-barreled probe assumes that the spatial distance between the centerlines of the two adjacent measurement tubes is small relative to the length scale of the flow features it is employed to measure. The second probe type is a coannular configuration known more specifically as the Prati probe after its creator, William Prati of the NASA Glenn Research Center (formerly NASA Lewis Research Center). The Prati probe utilizes a larger diameter tube to enclose both steady state and high response instrumentation - truly acquiring both measurements from the same location in the flow field. Introduced here, a more detailed description of these probes is included below as well as that of the facility which was used for their evaluation.

\section{Apparatus and Test Procedure}

\section{A. The Double-Barreled Combination Pitot Probe}

As mentioned above and depicted in Figure 1, the double-barreled probe consists of two tubes mounted immediately adjacent to one another. That is, the needed steady state and high response Pitot pressure measurements are made separately. Shown in this orientation, the smaller upper tube is usually $0.063 \mathrm{in}$. in outer diameter and is used to make the steady state pressure measurement. This tube is pneumatically routed out through the experiment and connected to a highly accurate facility steady state pressure transducer. The adjacent 0.090 in. diameter tube serves a dual purpose. It provides both a structural casing within which to mount a miniaturized high response pressure transducer and a conduit through which its wires are conveyed to facility high response data acquisition system electronics. The configuration shown in Figure 1 is also typical in that it does not contain any additional shielding for the dynamic pressure transducer against particulate damage other than the shield which is installed by the transducer's manufacturer. Both tubes were internally chamfered at $30^{\circ}$ (half angle) to the probe's axis 
and had sharp leading edges. As was the case here, this is typically done to maximize the range of flow angles over which they are able to obtain accurate measurements.

For the present tests, a modified double-barreled probe was used. Three changes were made relative to the production configuration to facilitate these tests. First, the probe was constructed, but not mounted into a rake body as it normally would be. Instead, the probe was mounted between two clamping plates that were installed edge on vertically in the probe calibration facility as described in detail below. One of the plates was notched to accept the double-barrel probe without crimping or crushing it. The combined thickness of the two clamping plates with the probe between them was approximately $0.30 \mathrm{in}$. The leading edge of these thin plates was located 1.7 in. downstream of the probe tip so as not to affect the measurements being obtained. Second, the probe tip was meticulously inspected under magnification to insure that the opening of each tube was cut perpendicular to its respective tube axis, that the two tubes' tips were aligned axially, that each tube was internally chamfered and that any burrs that may have been created at its leading edge during fabrication had been properly removed. In fact, it was noted that the leading edges of the tubes of the double-barreled probe used in the subject tests were cut slightly more perpendicular to their axes than a production probe that was used as a reference. The braze material that was used in mating the two tubes to form the probe tip was carefully kept multiple tube diameters downstream of the tubes' leading edges to avoid any aerodynamic interaction. Thirdly, the high response transducer which normally would have been installed in the 0.090 in. diameter tube was purposefully omitted. Instead, the 0.090 in. diameter tube was connected to the same highly accurate steady state data acquisition system as was the 0.063 in. diameter steady state tube. In this way, the aerodynamic pressure measuring capability of the probe itself was evaluated and not obscured within the much less accurate error band of a high response pressure transducer.

\section{B. The Coannular Combination Prati Probe}

The coannular Prati probe features a multipart construction and is illustrated in Figure 2. It's 0.142 in. diameter outer Pitot tube establishes a common flow stagnation zone within which both its steady state and high response measurements were obtained. Within the outer tube is an insert which holds and centers the high response pressure transducer and provides an electrical conduit that protects as it conveys the transducer wires out of the probe and into a $0.075 \mathrm{in}$. diameter tube which is routed outside of the experiment. Once clear of the free jet flow, the high response transducer wires were connected to the facility steady state and high response data acquisition system electronics. Located at the forward end of the high response pressure transducer holder is a shield which can be seen in the front view provided in Figure 2. Both the steady state and high response measurements are acquired from behind this shield. Pressure path openings have been included around the periphery of the shield for this purpose. The cross sectional area of these pressure paths was made to be much greater than that of the sensing holes in the manufacturer's own integral transducer shield thereby ensuring only a negligible reduction of the resultant configuration's frequency response. Steady state measurement is made by way of a pressure path which is routed between the high response transducer holder and the outer Pitot tube. Downstream of the high response transducer, stagnation pressure is pneumatically transmitted out of the probe tip and experiment through a 0.063 in. diameter tube which is connected to a highly accurate steady state pressure transducer. Like the double-barreled probe, the Prati probe tip is internally chamfered to maintain its accuracy in the presence of flow angularity.

The Prati probe used for the present experiment was of typical construction. However, like the doublebarreled probe, it was tested as a single probe tip, clamped between two plates - one of which was notched. Owing to the larger diameter of the Prati probe ( 0.142 versus 0.090 in. diameter), the total thickness of the two plates with the Prati probe sandwiched between them was approximately $0.35 \mathrm{in}$. The plates were located approximately 1.7 in. downstream of the Prati probe's tip so as to not affect the measurements being made. It was also inspected carefully under magnification to verify that it was in the proper configuration. The opening of the main tube was perpendicular to its axis, was internally chamfered and devoid of any burrs. One difference between the approaches taken to evaluate the Prati and double-barreled probes was 
that the Prati probe had a high response transducer mounted in its intended location. Given that both the steady state and high response pressures are measured from the same flow stagnation zone, it was felt that leaving the high response transducer in place would not detract from the value of the experiment and may be used for any subsequent tests to document the high frequency performance of the probes. Steady state pressure was measured by this transducer in that its steady state or Direct Current (DC) component was recorded by the steady state data acquisition system. Further details of this arrangement are provided in the facility description and test procedure sections below.

\section{The NASA Glenn Free Jet Probe Calibration Facility}

Tests were conducted in the probe calibration laboratory located in test cell CE-12 at the Glenn Research Center at Lewis Field (Refs. 3 to 5). More specifically, the lab's 3.5 in. diameter free jet probe calibration rig was used for the experimental evaluation of the two probes. Shown in Figure 3, the rig consists of continuous supplies of air flow at tiered pressure levels, a plenum tank, free jet nozzle and probe actuation system. The free jet is exhausted into the CE-12 facility and vented to atmosphere through ceiling vents. Facility and probe control and data acquisition systems are provided by way of a nearby control room which services a number of test cells.

As mentioned above, the CE-12 free jet rig is supplied by high pressure air sources including the 40 psig air source used for the present experiments. This air is provided by a central air supply service to the rig's 29.2 in. diameter plenum tank through an 8 in. diameter air line. Two valves, a 6 in. main ball valve and a $1.5 \mathrm{in}$. bypass globe valve are used to throttle down and control the air flow to the desired plenum stagnation pressure. The plenum tank is fitted with two perforated plates, one honeycomb section and four turbulence reduction screens which insure free jet flow quality. The free jet is circular in shape and is generated by a subsonic nozzle whose exit is $3.5 \mathrm{in}$. in diameter. The nozzle contour is elliptical with a semi-major axis of $15 \mathrm{in}$. and a semi-minor axis of $6 \mathrm{in.}$ As documented for a probe calibration test program (Ref. 5), typical axial locations from the nozzle exit where calibrations can be completed include 2.5 and $5.0 \mathrm{in}$. Over this range of axial stations, the working diameter of the jet is slightly less than $2.0 \mathrm{in}$. in diameter. The axial station at which measurements were made for the present effort was 5.4 in.

Also shown in Figure 2 is the CE-12 high-accuracy pitch-yaw actuator system, which consists of an $8 \mathrm{in}$. diameter rotary pitch table mounted on a $12 \mathrm{in}$. diameter rotary yaw table. The $8 \mathrm{in}$. tables lies in the $(x, z)$ pitch plane and the 12 in. table lies in the $(x, y)$ yaw plane. Stepper motors fitted with optical feedback encoders drive the rotary tables to the desired combination of pitch and yaw angle. Probes are aligned with respect to the jet axis centerline using the CE-12 alignment fixture, which partially consists of a flange that attaches to the free jet nozzle exit. Precision squares of varying sizes are rigidly fastened to this flange in either the pitch $(x, z)$ or yaw $(x, y)$ planes. Probes are aligned with the free jet axis centerline through parallel alignment of the probe shaft with the edges of the squares within an associated tolerance of $\pm 0.05^{\circ}$. The positioning accuracies of the 8 and 12 in. tables are $\pm 0.02^{\circ}$ and $\pm 0.01^{\circ}$, respectively (Ref. 5).

The CE-12 calibration facility is kept equipped with up-to-date standard NASA Glenn instrumentation and data acquisition systems. At the time of the probe tests, these included the Escort D+ multichannel data acquisition system, Pressure Systems Incorporated (PSI) Model 780B Electronically Scanned Pressure (ESP) system, Probe Actuation and Control System (PACS) and MassComp high response digital data acquisition system. More specifically, the ESP system utilized a 32 channel 10 psid pressure transducer module to acquire the steady state double-barreled and Prati probe measurements. The accuracy of each channel of this $10 \mathrm{psid}$ module was $\pm 0.020 \mathrm{psi}$. Steady state measurements were obtained by sampling the ESP data at 1 sample per second for $20 \mathrm{sec}$ and averaging the result. A root mean square error analysis of the accuracy of the $10 \mathrm{psid}$ module specifications revealed that the \pm 0.1 percent total pressure recovery accuracy requirement could only be determined conclusively when the free jet was operated at a Mach number at or above 0.59 . Therefore, the accuracy benchmark for the results reported herein was relaxed to \pm 0.15 percent which was achievable at all test conditions. Were these tests conducted after the facility was upgraded to its present ESP Model 8400 steady state data acquisition system, the test results could have been assessed against the \pm 0.1 percent requirement at all conditions. 
The steady state or DC component of the pressure measured by the Kulite transducer installed in the Prati probe was recorded by Escort, but not until after it had been processed by the facility dynamic data acquisition system. Before reaching Escort, the Kulite's signal was amplified using a Preston Amplifier and subsequently processed through a TSI Incorporated Integrated Filter and Amplifier 100 (IFA 100) signal conditioner which provided the needed anti-alias filtering and amplification of the signal. The Escort system then sampled and averaged the result in the same way as for the steady state data each steady state (DC component) reading being the average of twenty samples acquired at a rate of one sample per second for $20 \mathrm{sec}$. Limited high response data was also recorded digitally at a sampling rate of $10 \mathrm{kHz}$ from the Prati probe Kulite pressure transducer following anti-alias filtering of the data at $2 \mathrm{kHz}$ and application of a twelve bit analog-to-digital converter. However, this data is not reported as it was only recorded for the Prati probe. With this exception, the data from both probes were sampled in the same way by the same data acquisition systems.

\section{Test Procedure}

While the test procedure for the probes' evaluation was relatively simple, a few points need to be made. As shown in Figure 3, the axes of the rotating pitch and yaw tables were positioned to intersect with the axis of the free jet. Therefore, the initial installation of each of the probes (tested separately) with their tips very near the jet axis in the core flow insures that they always remained there regardless of their angular orientation. The tips of the probes were maintained in the calibrated core flow of the jet. As described in Section $\mathrm{C}$, the pitch table was attached to and rotated with the yaw table. This being so, both positive and negative pitch angles could be set without difficulty. However, only positive yaw angles were tested due to the need to keep the pitch table out of and to otherwise prevent any interference with the free jet. To accommodate this requirement, the probes' symmetry plane was aligned parallel to the yaw table's axis so that negative yaw testing was not required. Initially, each probe was positioned at pitch and yaw angles of $0.0^{\circ}$ and the free jet Mach number varied from 0.1 to 0.9 . Once data acquisition at these conditions was complete, tests were conducted over a matrix of pitch and yaw angles at fixed free jet set point Mach numbers of $0.3,0.6$, and 0.9 . Repeat data was acquired at each of these test conditions through both increasing and decreasing sequences of Mach number and angles of attack and yaw.

\section{Results and Discussion}

Both probes were subjected to the same sequences of tests including increasing and decreasing repeats with only slight variations. These variations consist of the use of a smaller, but still adequate, maximum yaw angle limit ( $30^{\circ}$ versus $40^{\circ}$ for the Prati probe) to avoid physical contact between the probe support attachment to the pitch table and the facility nozzle and higher density Mach number data having been recorded for the Prati probe configuration at zero incidence. Neither of these occurrences detracts from nor changes the conclusions of this work. Therefore, advantage is taken of this approach to facilitate discussion and enable cross-comparisons between the results obtained. The results from each probe are presented and discussed in the order tested beginning with the double-barreled probe.

\section{A. The Double-Barreled Combination Probe}

The double-barreled probe was first fixed at zero angles of both attack and yaw and evaluated at free jet Mach numbers of 0.3, 0.6, and 0.9. The results from these tests are given in Figure 4. In terms of free jet stagnation pressure normalized by the tank pressure, the measurements show that the probe's 0.090 in. diameter high response tube recorded the correct plenum tank measured value within the benchmark \pm 0.15 percent tolerance at all three jet Mach numbers. However, the value measured by the smaller 0.063 in. diameter steady state tube was markedly lower. In fact, it consistently and increasingly underrecorded the free jet stagnation pressure with increasing Mach number. As shown in Figure 4, the error recorded by this probe reached 1.1 percent at Mach 0.9- over seven times the allowable error. As a 
result, an instrumentation check was done wherein the tubing was switched between the two ESP transducers used to measure the pressures and the test repeated. The results of that and further data system checks determined that the data acquisition system was not in error. Regardless of which ESP transducer was used, the smaller 0.063 in. diameter tube sensed the same lower pressures.

Next, the free jet Mach number was set at 0.3 and the double-barreled probe's pitch angle varied between $-40^{\circ}$ and $40^{\circ}$. The results of these tests are provided in Figure 5. These data show that the cause of the errant steady state measurements was the asymmetry of the double-barreled probe - the different diameters of its two tubes. This asymmetry in the probe's yaw plane caused the different measurements when the probe was actuated in pitch. At zero incidence, the flow stagnated in the larger 0.090 in. diameter tube while indications are that it prevented the flow from doing so in the smaller 0.063 in. diameter tube. This explanation is consistent with the data which show continuous ranges of pressure recovery over which each tube measures the correct value but where neither are symmetric about either $0^{\circ}$ of pitch or each other. Each tube is more accurate when it is forward of the other. In fact, this effect balanced out and the double-barreled probe nulled (e.g., both tubes read the same pressure) at a pitch angle of approximately $7.0^{\circ}$. It is further noted that the extent of the range of pitch angularity over which the $0.090 \mathrm{in}$. diameter tube recorded the correct value of stagnation pressure was larger than the range for the 0.063 in. diameter tube - a further indicator that it tended to dominate the flow about the combined double-barreled probe's tip. Linearly interpolating the data, the 0.090 in. tube adequately measured stagnation pressure over a pitch angle range (quoted to the nearest half degree) from $-28.0^{\circ}$ and $13.5^{\circ}$ whereas the 0.063 in. tube range was $1.0^{\circ}$ to $30.0^{\circ}$. Together, both tubes were accurate over the pitch range from $1.0^{\circ}$ to $13.5^{\circ}$.

Free jet tests at Mach 0.3 which varied the probe yaw orientation while holding its pitch angle constant at $0^{\circ}$ provided additional insight. As illustrated in Figure 6, the flow stagnated in the 0.090 in. diameter tube more than the 0.063 in. diameter tube for all yaw angles up to and including $30^{\circ}$ of yaw. However, a notable change occurred at $15^{\circ}$ where the smaller tube's measurement abruptly increased. This increase was recorded during both the increasing and decreasing yaw angle surveys. Although the smaller tube's pressure subsequently partially decreased, it remained consistently closer to the 0.090 in. tube measured value through the maximum value of yaw tested. This is likely due to an aerodynamic interaction between the probes' tubes. Given the probe's symmetry in its pitch plane, similar results are expected if tests had been conducted over the same range of negative yaw angles. Assuming symmetry, the yaw angularity range over which the 0.090 in. tube adequately measured stagnation pressure was from $-27.0^{\circ}$ to $27.0^{\circ}$. For comparison, the corresponding range for the 0.063 in. tube was $12.0^{\circ}$ to $18.5^{\circ}$. Therefore, both probes accurately measured pressure only over the range of angles where there seems to have been a flow interaction-from $12.0^{\circ}$ to $18.5^{\circ}$.

Completion of the same pitch and yaw test matrix at a free jet Mach number of 0.6 yielded results similar to those at Mach 0.3. These data are given in Figures 7 and 8, respectively. Again, the doublebarreled probe nulled at $7.0^{\circ}$ of pitch. However, the range of angles over which the probe tubes were accurate in both pitch and yaw - was reduced. In pitch, the 0.090 in. tube was accurate from $-22.0^{\circ}$ to $8.0^{\circ}$ while the 0.063 in. tube was accurate from $6.0^{\circ}$ to $25^{\circ}$. Together, both tubes were only accurate for pitch angles from $6.0^{\circ}$ to $8.0^{\circ}$. When yawed at Mach 0.6 , the same apparent tube interaction occurred but was first detected at $10^{\circ}$ - less than the $15^{\circ}$ that was the case at Mach 0.3. In yaw, the 0.090 in. tube was accurate from (again by symmetry) $-20.5^{\circ}$ to $20.5^{\circ}$. The $0.063 \mathrm{in}$. tube did not accurately measure stagnation pressure at any yaw angle. Therefore, no range of yaw angles existed where both tubes provided accurate measurements.

The further increase in free jet Mach number to 0.90 resulted in further degradation of what little measurement capability the double-barreled probe retained. These double-barreled pitch and yaw flow angularity test data are provided in Figures 9 and 10, respectively. Again, the probe nulled at a pitch angle of 7.0 $0^{\circ}$. The range of pitch angles over which the 0.090 in. tube was accurate was further reduced to from $-20.0^{\circ}$ to $7.0^{\circ}$. The corresponding pitch range for the 0.063 in. tube was from $7.5^{\circ}$ to $24.0^{\circ}$. Together, 
both tubes weren't accurate for any pitch angles. When the probe was yawed at Mach 0.9 , the onset of the tube interaction was first detected at $15^{\circ}$-returning to the same value as for the Mach 0.3 case. This may be due to nonlinear effects of some kind-possibly a combined effect of Mach number and Reynolds number. Regardless, this is not a desired property for instrumentation to have. In yaw, the $0.090 \mathrm{in}$. tube was accurate from (assuming symmetry) $-19.0^{\circ}$ to $19.0^{\circ}$. Again, the $0.063 \mathrm{in}$. tube did not accurately measure stagnation pressure at any yaw angle. As was the case at Mach 0.6, no range of yaw angles existed over which both tubes provided accurate measurements.

\section{B. The Coannular Prati Combination Pressure Probe}

As mentioned above, tests of the coannular Prati probe configuration were completed according to very nearly the same test matrix as were the double-barreled probes. First, the free jet Mach number was varied from 0.10 to 0.90 in finer 0.10 Mach number increments while the Prati probe was held fixed at $0.0^{\circ}$ in both pitch and yaw. These data are presented in Figure 11. Clearly, the steady state measurement of stagnation pressure ratio varies much less than the double-barreled probe, remaining within the benchmark \pm 0.15 percent accuracy throughout the entire Mach range. These results are consistent with the measurement having been taken from within a single Pitot tube. An extremely slight reduction in the steady state measurement with increasing Mach number may be due to increased losses between the last plenum-mounted flow conditioning device and the nozzle free jet measurement plane. Some initial DC offset and subsequent drift were recorded by the high response transducer which went out of and back into the desired steady state range of accuracy. However, this variation is well within the specified accuracy limits of the typical high response transducer used for these tests which at $\pm 0.2 \mathrm{psi}$ are ten times less accurate than the 10 psid modules of the ESP 780B system. As such, this error is attributed to the high response transducer and not the probe itself.

At a free jet Mach number of 0.3 , separate pitch and yaw excursion tests were conducted over the same range of pitch $\left(-40^{\circ}\right.$ to $\left.40^{\circ}\right)$ and the full range of yaw $\left(0^{\circ}\right.$ to $\left.40^{\circ}\right)$ angles. These results are provided in Figures 12 and 13, respectively. The first observation made is that the results are very nearly identical. This is further confirmed by linearly interpolating the ranges of pitch and yaw over which the Prati probe remains within the benchmark $\pm \mathbf{0 . 1 5}$ percent of free jet plenum pressure accuracy criterion. Relying only on the steady state measurement, this range-from $-26^{\circ}$ to $26^{\circ}$ - is the same for both pitch and yaw. At higher values of both angles, the error between the steady state and the DC component of the high response transducer's signal appears to narrow. This may be due to the pneumatic filtering which only occurs in the steady state pressure line between its measurement in the probe tip and its associated ESP steady state transducer.

Similar tests conducted at a free jet Mach number of 0.6 yielded the data (in pitch and yaw) presented in Figures 14 and 15. These data are also very similar. Again, the ranges of pitch and yaw angle over which the coannular probe remains accurate were determined to be close- both rounding to from $-18.0^{\circ}$ to $18.0^{\circ}$. As was the case with the double-barreled probe, the range of angles over which the Prati probe's measurements remain accurate decreased with increasing Mach number. For the Prati probe, this decreased from $\pm 26.0^{\circ}$ at Mach 0.3 to $\pm 18.0^{\circ}$ at Mach 0.6. The initial DC offset and subsequent calibration drift of the high response transducer appears meaningfully reduced in Figures 14 and 15 relative to Figures 12 and 13, respectively. This is due to the fixed transducer error becoming a smaller percentage of the higher free jet total pressure required to achieve the Mach 0.6 test conditions.

At the maximum free jet Mach number of 0.9 , the results of the flow angularity excursion tests of the Prati probe continued the trend established by the Mach 0.3 and 0.6 data. These Mach 0.9 data are depicted in Figures 16 and 17. Except for very small differences at the combination of this highest Mach number and the largest angles, the performance of the probe remained independent of whether it was actuated in pitch or yaw. The ranges of accurate working angles of the probe (again, quoted to the nearest half degree) were further reduced to between -14.0 to 14.0 in pitch and -14.5 to 14.5 in yaw, but are still considered adequate. Throughout all of the tests, no influence of the mounting fixture or clamping plates 
on the measurements obtained was observed. Given the common mounting hardware employed for both probe types, these results give assurance that there was no measurable interaction between the experiment hardware and the free jet and thereby cross validate and establish the results obtained.

\section{Summary and Conclusions}

A series of instrumentation tests were completed at steady state conditions in NASA Glenn's 3.5 in. diameter free jet probe calibration facility which had as their goal evaluating the performance of two combination steady state and high response Pitot probes - the double-barreled and coannular Prati probes. Overall, the usefulness of the double-barreled probe proved to be quite limited. While simpler and more economical to fabricate, its construction from two different sized tubes mounted immediately adjacent to one another formed an asymmetric configuration which biased the measurements it obtained. This error exceeded the relaxed accuracy benchmark of \pm 0.15 percent for either or both of the steady state and high response tube measurements over most of the conditions tested. With the double-barreled probe fixed at zero incidence, the error was 0.2 percent at Mach 0.3 and increased consistently to 1.1 percent at Mach 0.9. A limited zone of biased flow angularity was measured over a portion of the tests' Mach range within which both tubes accurately sensed Pitot pressure. However, double-barreled probe measurements may only be realistically valid for a small range of Mach numbers less than 0.3.

When fixed at zero incidence, the Prati probe measured stagnation pressure to within the required tolerance at all free jet Mach numbers. The Prati probe also provided accurate readings over more than adequate ranges of flow angularity at all Mach numbers. These ranges decreased from $\pm 26.0^{\circ}$ at Mach $0.3^{\circ}$ to $\pm 18.0^{\circ}$ at Mach 0.6 and finally $\pm 14.0^{\circ}$ at Mach 0.9 . Typical aircraft inlet performance evaluation requires these higher accuracies and therefore the coannular Prati probe should be used whenever possible.

\section{Recommended Future Work}

Although a high response pressure transducer was installed in the Prati probe for these tests and some data was recorded, an up-to-date documentation of its frequency response characteristics is recommended. Such a test would require the establishment of a controllable and calibrated, dynamically fluctuating (i.e., capable of generating a useful and robust standing wave) pressure environment across a sufficient range of combined amplitude and frequency to prove the Prati probe's frequency response characteristics. Possible configurations might include a flip flop nozzle, use of stereo speaker drivers (as has been used to generate low amplitude pressure oscillations in the past) and/or a Helmholtz resonator as excitation devices with an associated open and unshielded control probe stationed nearby.

\section{References}

1. Daggett, D.L.; Kawai, R.; and Friedman, D.: Blended Wing Body Systems Studies: Boundary Layer Ingestion Inlets With Active Flow Control. NASA/CR-2003-212670, 2003, p. 39.

2. Critical Propulsion Components Volume 1: Summary, Introduction, and Propulsion System Studies. NASA/CR -2005-213594, 2005, p. 330.

3. Engine Research Building (ERB): Combustor Facilities - CE-12 Probe Calibration Laboratory. Testing Division, NASA Glenn Research Center at Lewis Field, URL: http://facilities.grc.nasa.gov/ erb/cells/ce12.html Accessed October 6, 2009.

4. Gonsalez, J.C.; and Arrington, A.E.: Five-Hole Flow Angle Probe Calibration for the NASA Glenn Icing Research Tunnel. NASA/CR - 1999-202330 (AIAA Paper 96-2201), 1999.

5. CE-12 Free Jet Calibration Facility. Unpublished Internal NASA Document, 1995.

6. Holman, J.P.: Experimental Methods for Engineers. 5th ed., McGraw-Hill, New York, NY, 1989, pp. 272-277.

7. Equations, Tables and Charts for Compressible Flow. NASA Report 1135, 1953. 


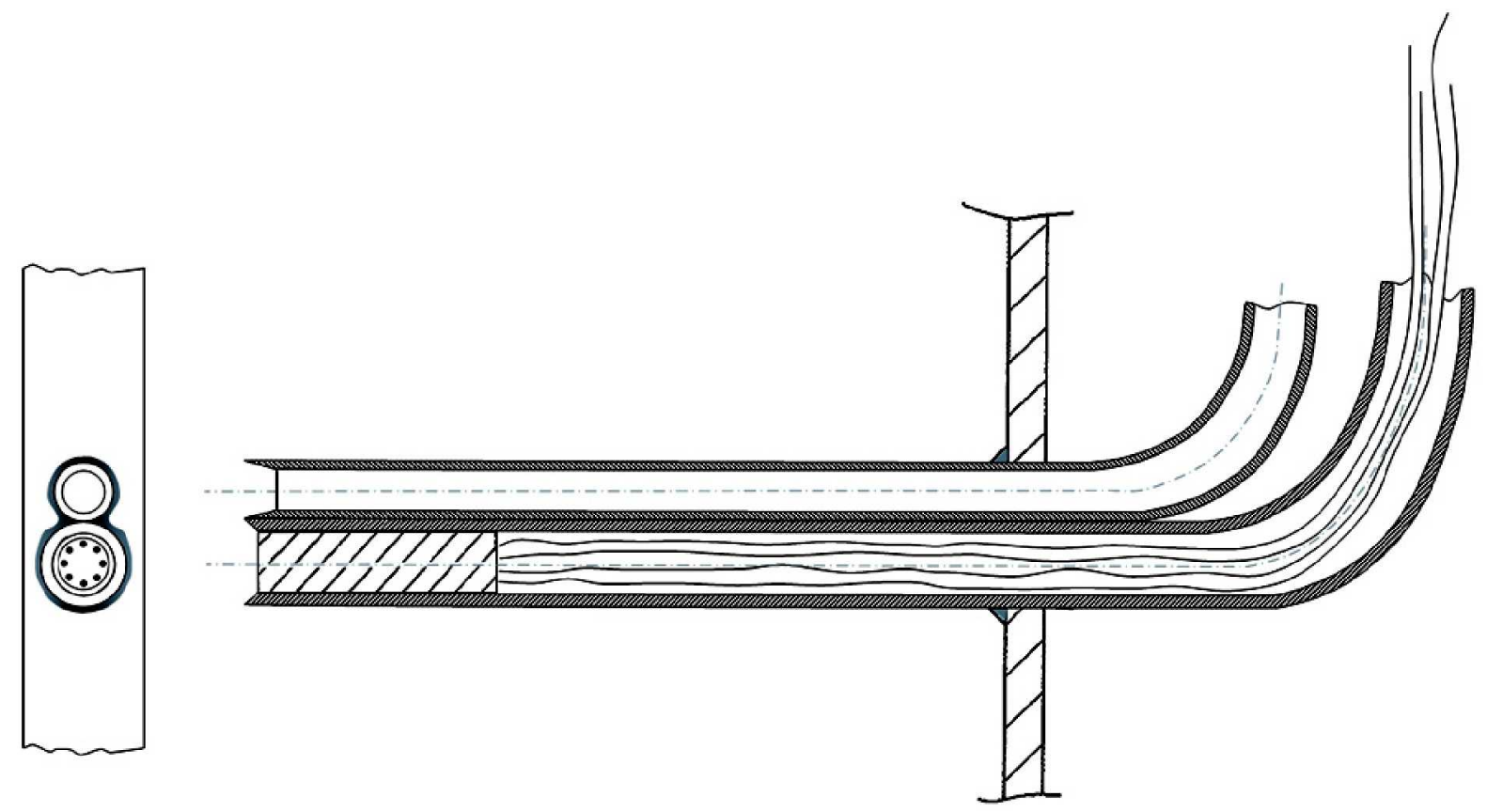

Figure 1.-The Double-Barreled Combination Steady State and High Response Pitot Probe Configuration.
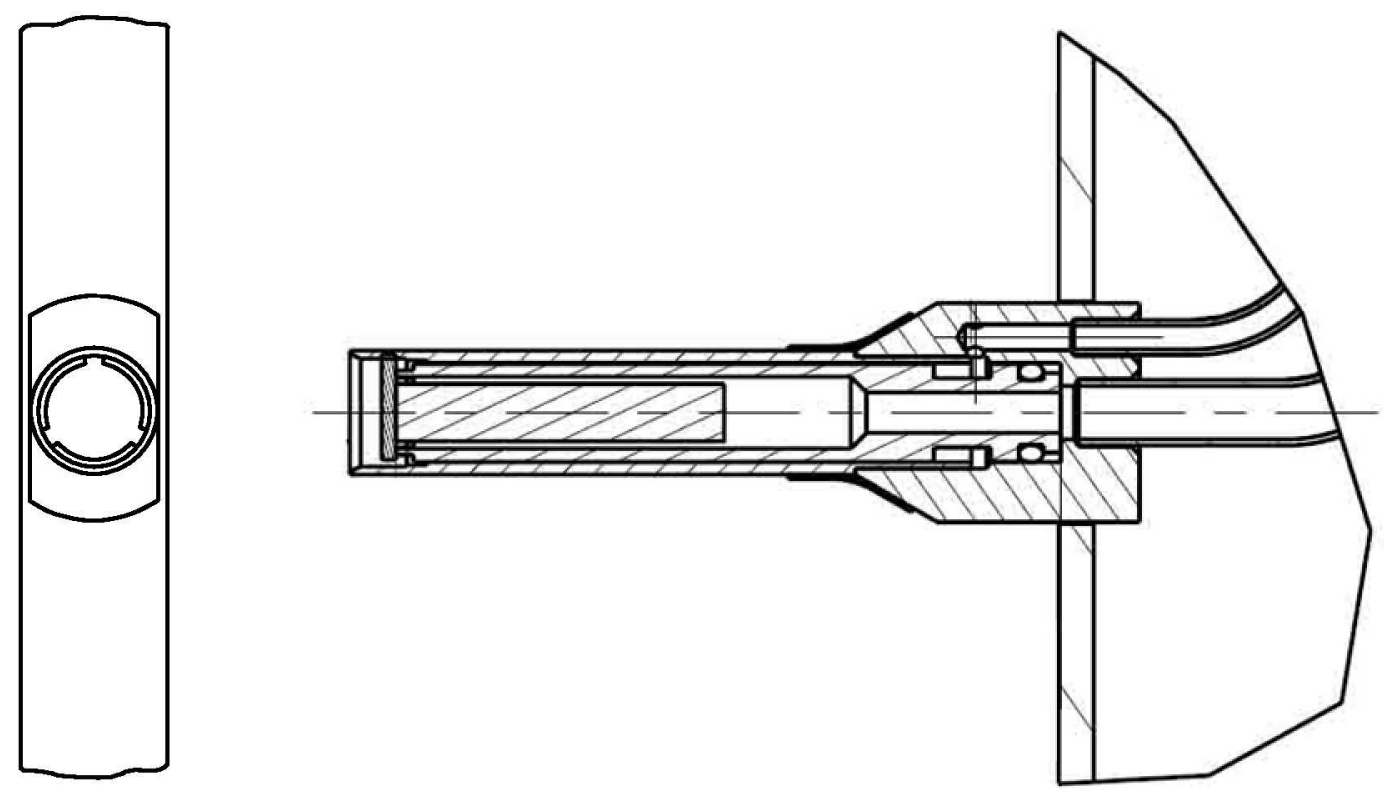

Figure 2.-The Coannular Prati Combination Steady State and High Response Pitot Probe Configuration. 


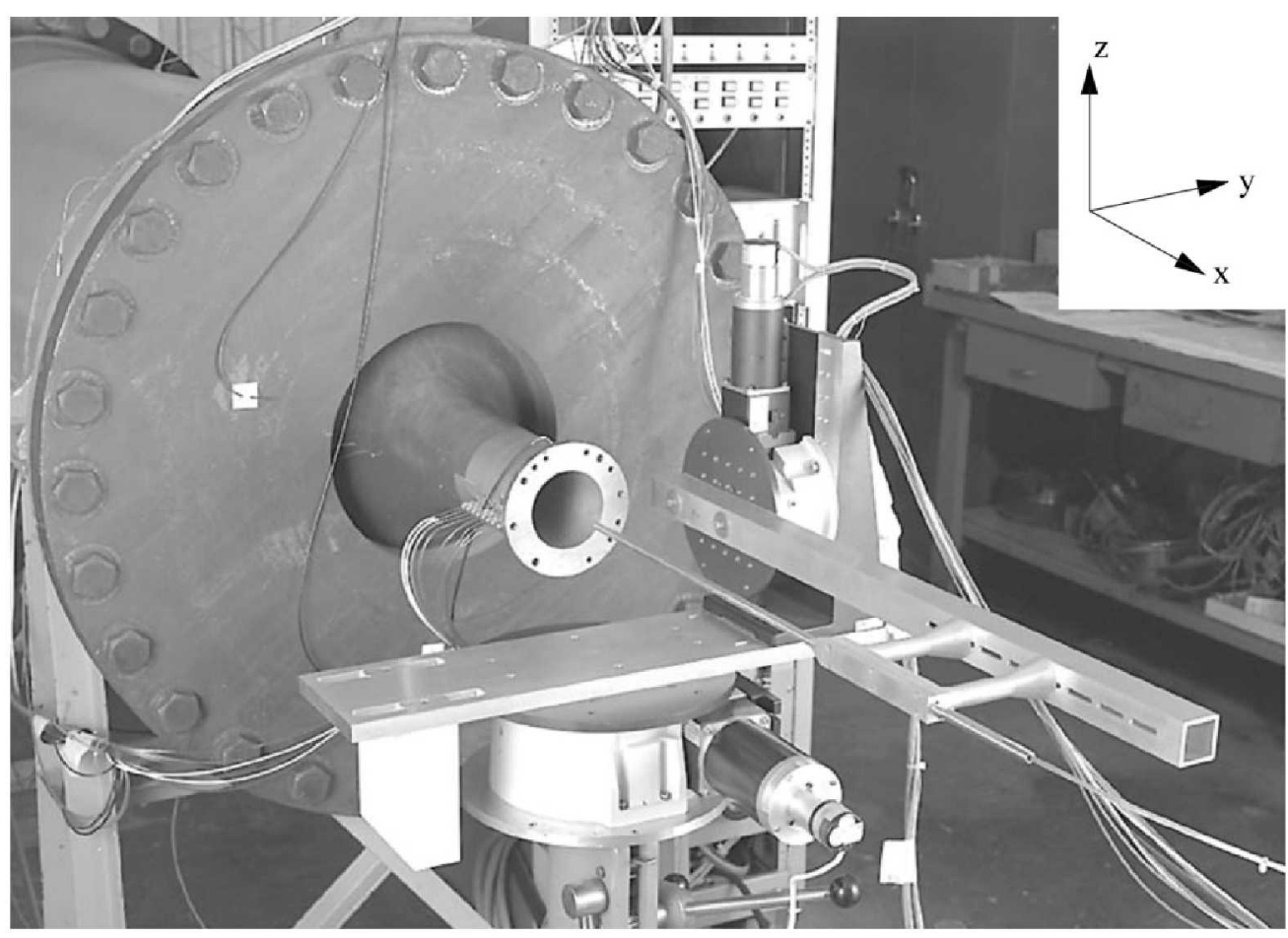

Figure 3.-Typical Probe Installation in the NASA 3.5 in. Diameter Free Jet Calibration Facility (CE-12). (Pitch and Yaw Rotary Tables Shown, Coordinate Axes are Displaced From Their Jet Exit Origin).

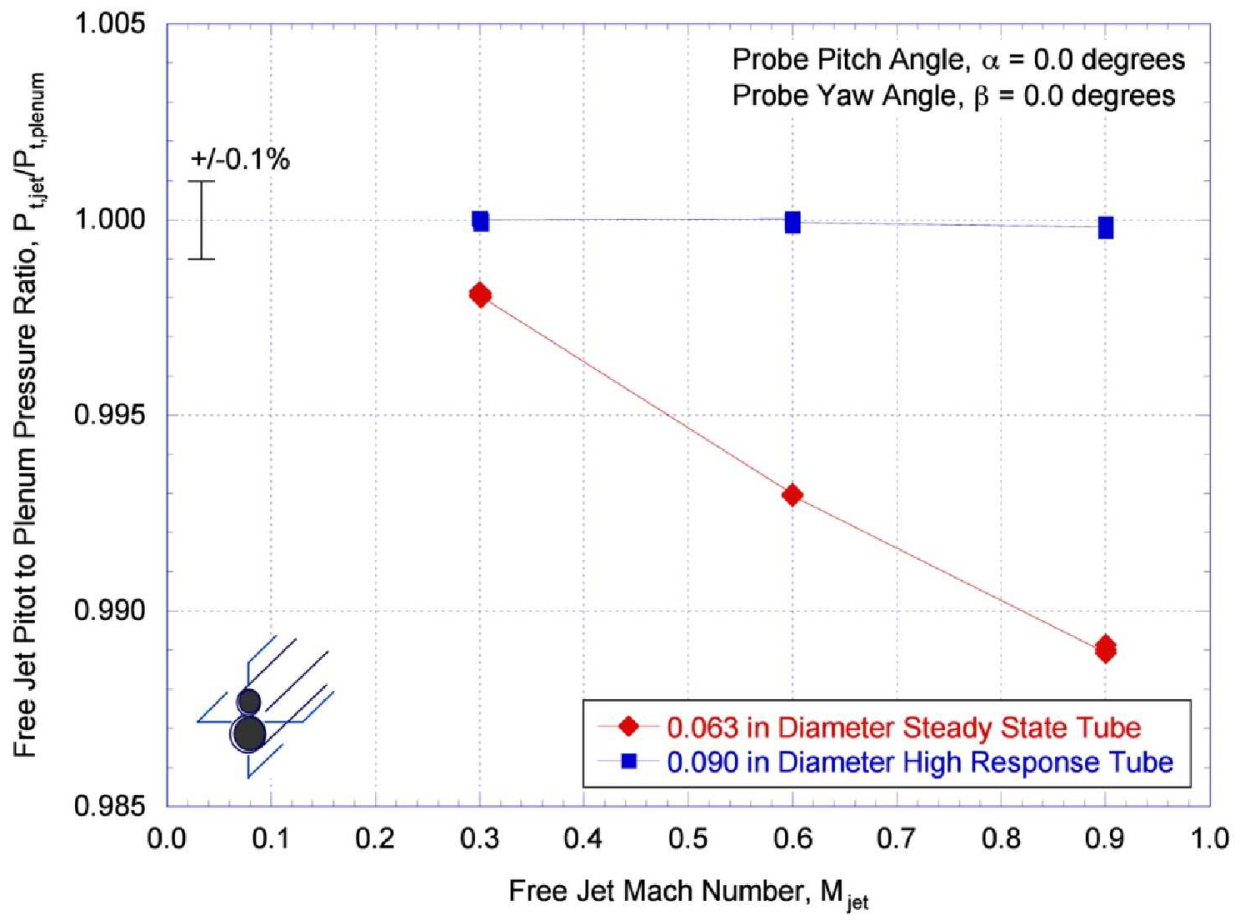

Figure 4.-Effect of Free Jet Mach Number on the Accuracy of Double-Barreled Combination Pitot Probe Measurement of Stagnation Pressure Ratio. 


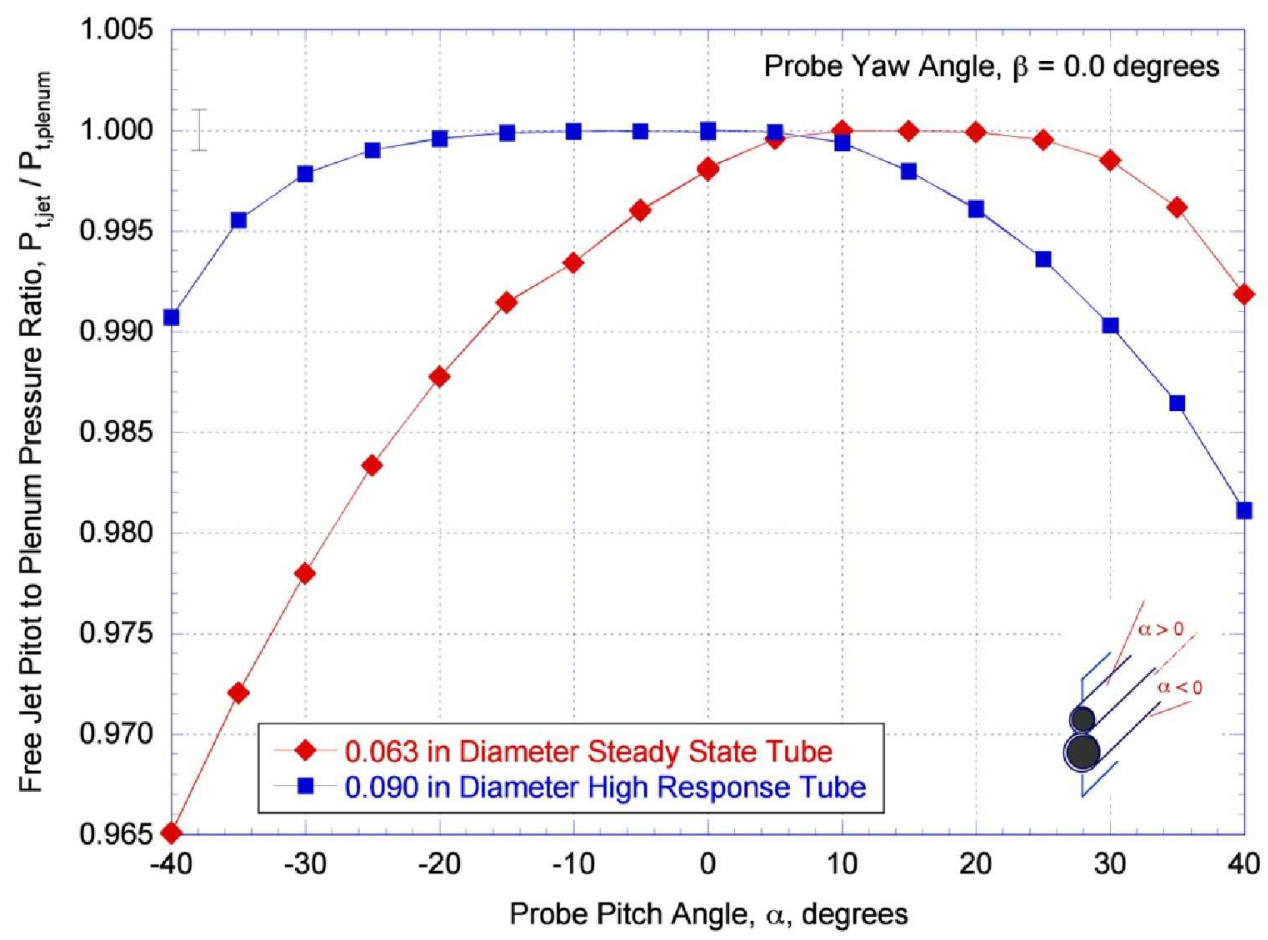

Figure 5.-Effect of Pitch Angle on the Accuracy of Double-Barreled Combination Pitot Pressure Probe Measurements of Stagnation Pressure Ratio at $\mathbf{M}_{\mathrm{jet}}=0.3$.

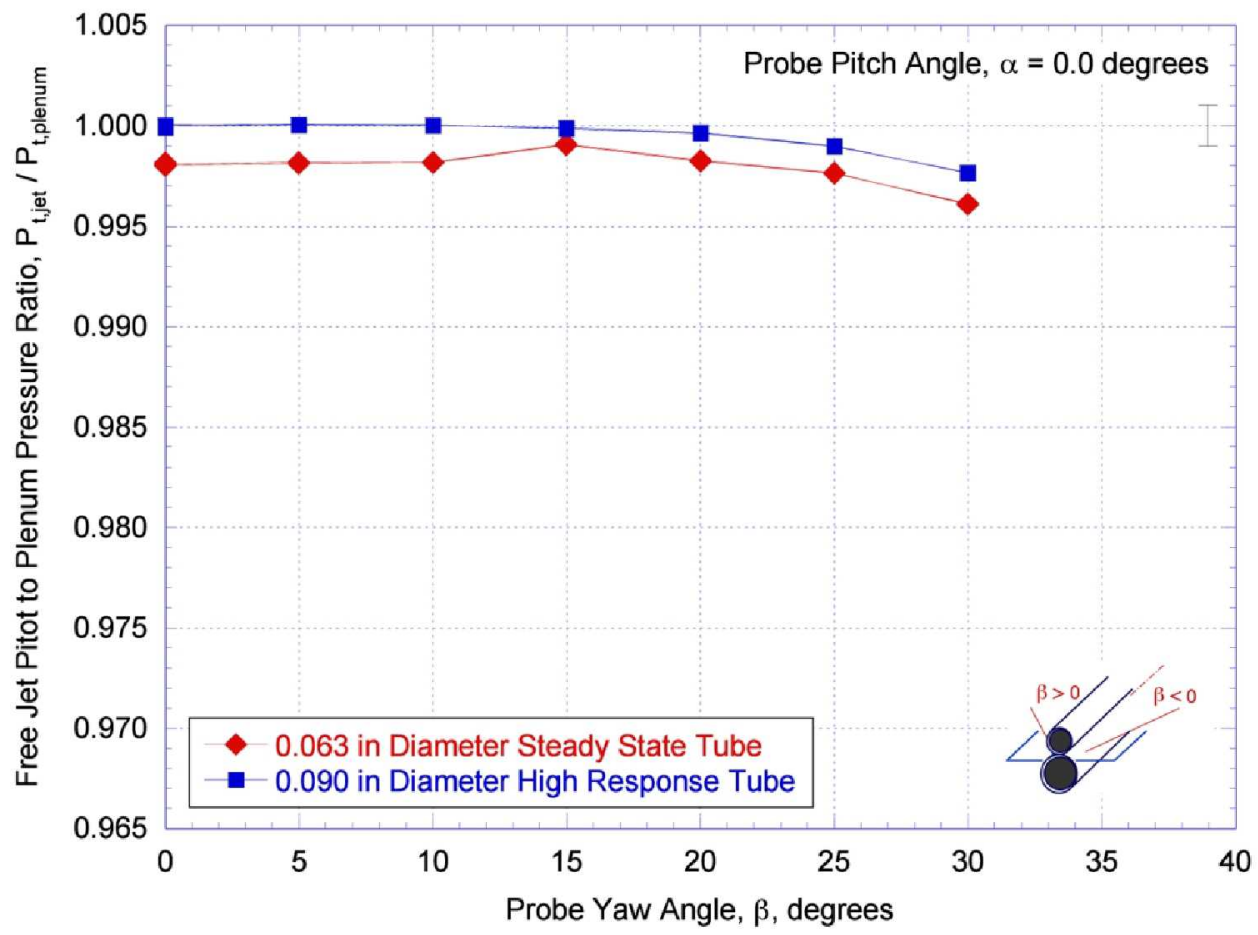

Figure 6.-Effect of Yaw Angle on the Accuracy of Double-Barreled Combination Pitot Pressure Probe Measurements of Stagnation Pressure Ratio at $\mathrm{M}_{\mathrm{jet}}=0.3$. 


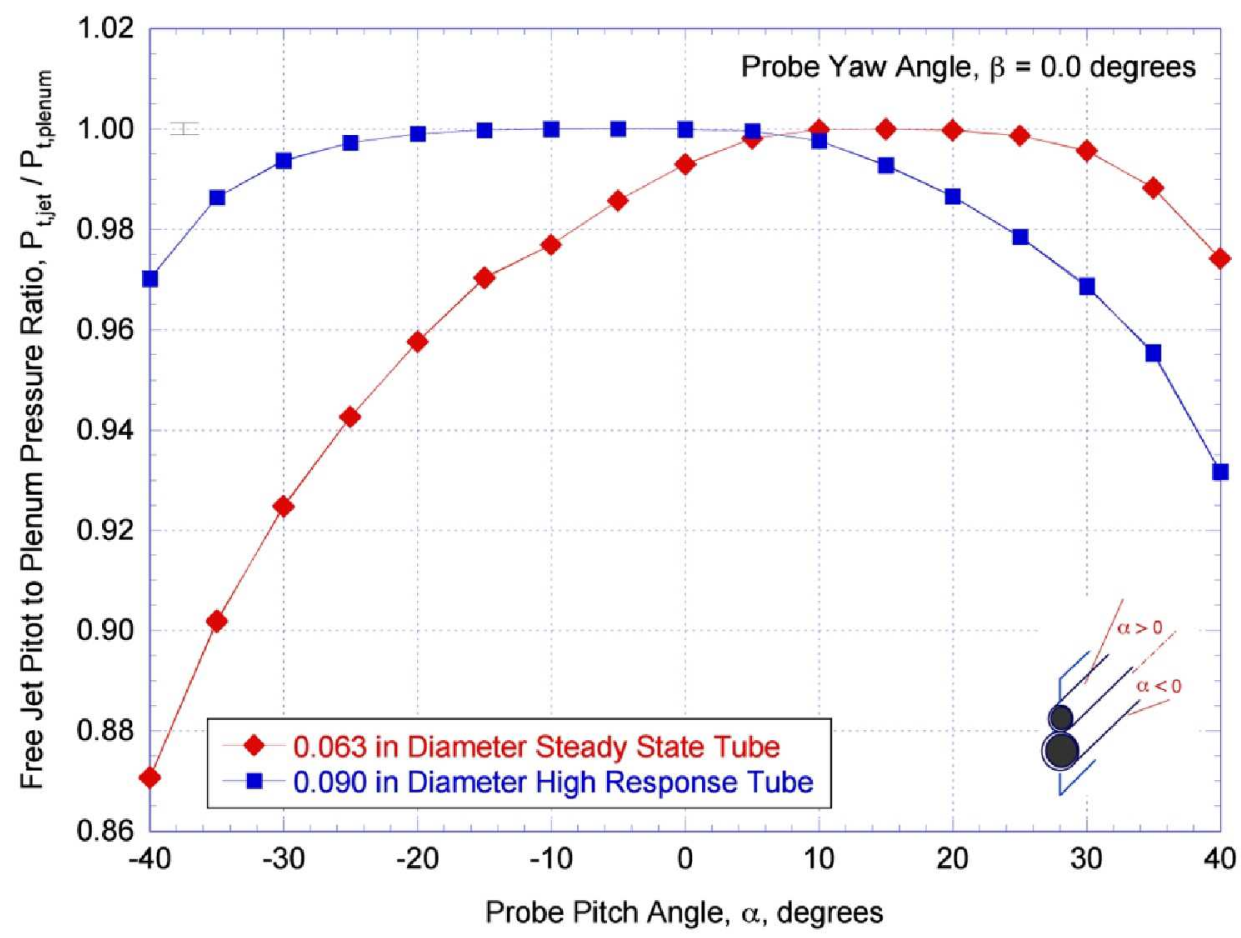

Figure 7.-Effect of Pitch Angle on the Accuracy of Double-Barreled Combination Pitot Pressure Probe Measurements of Stagnation Pressure Ratio at $M_{\mathrm{jet}}=0.6$.

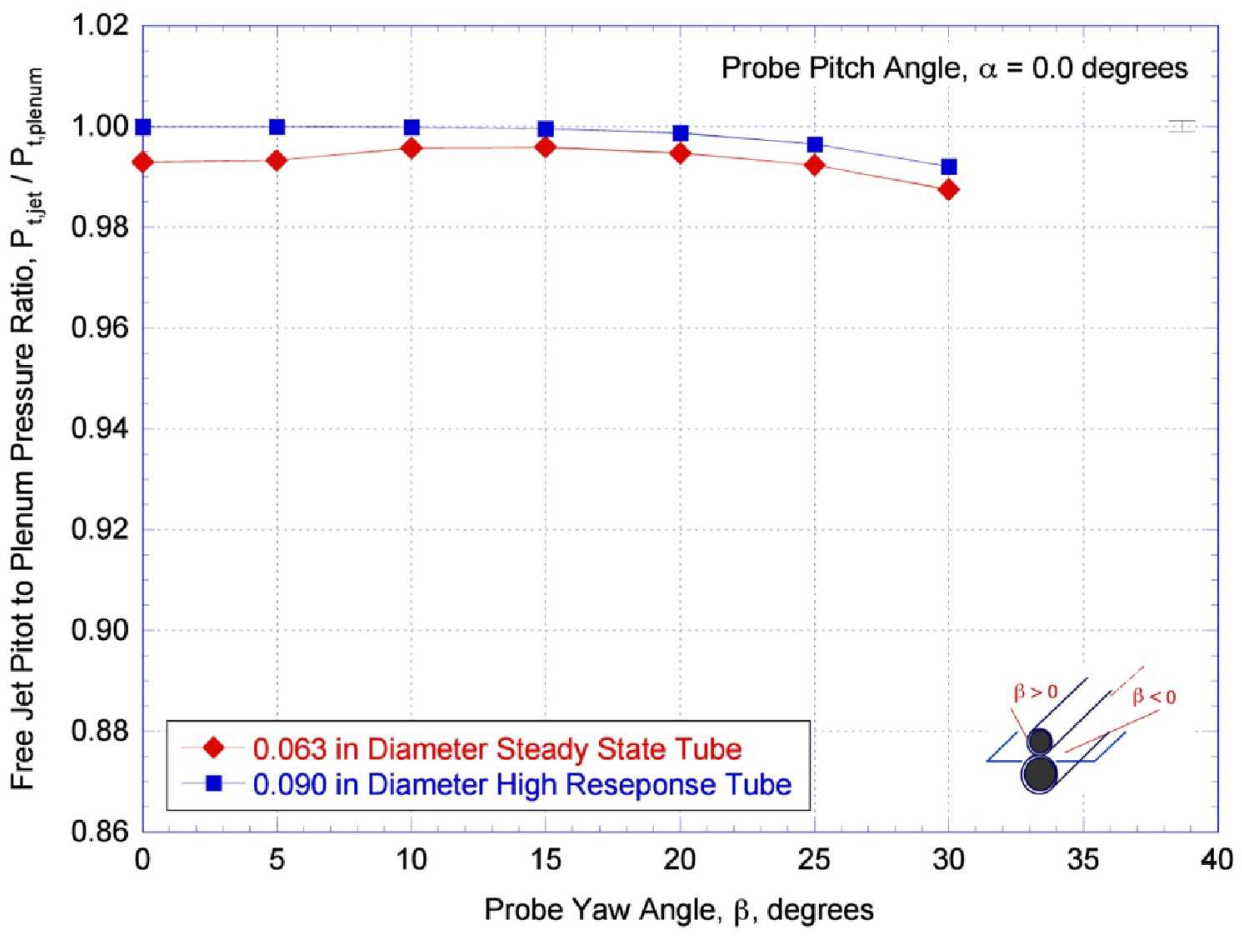

Figure 8.-Effect of Yaw Angle on the Accuracy of Double-Barreled Combination Pitot Pressure Probe Measurements of Stagnation Pressure Ratio at $\mathrm{M}_{\mathrm{jet}}=\mathbf{0 . 6}$. 


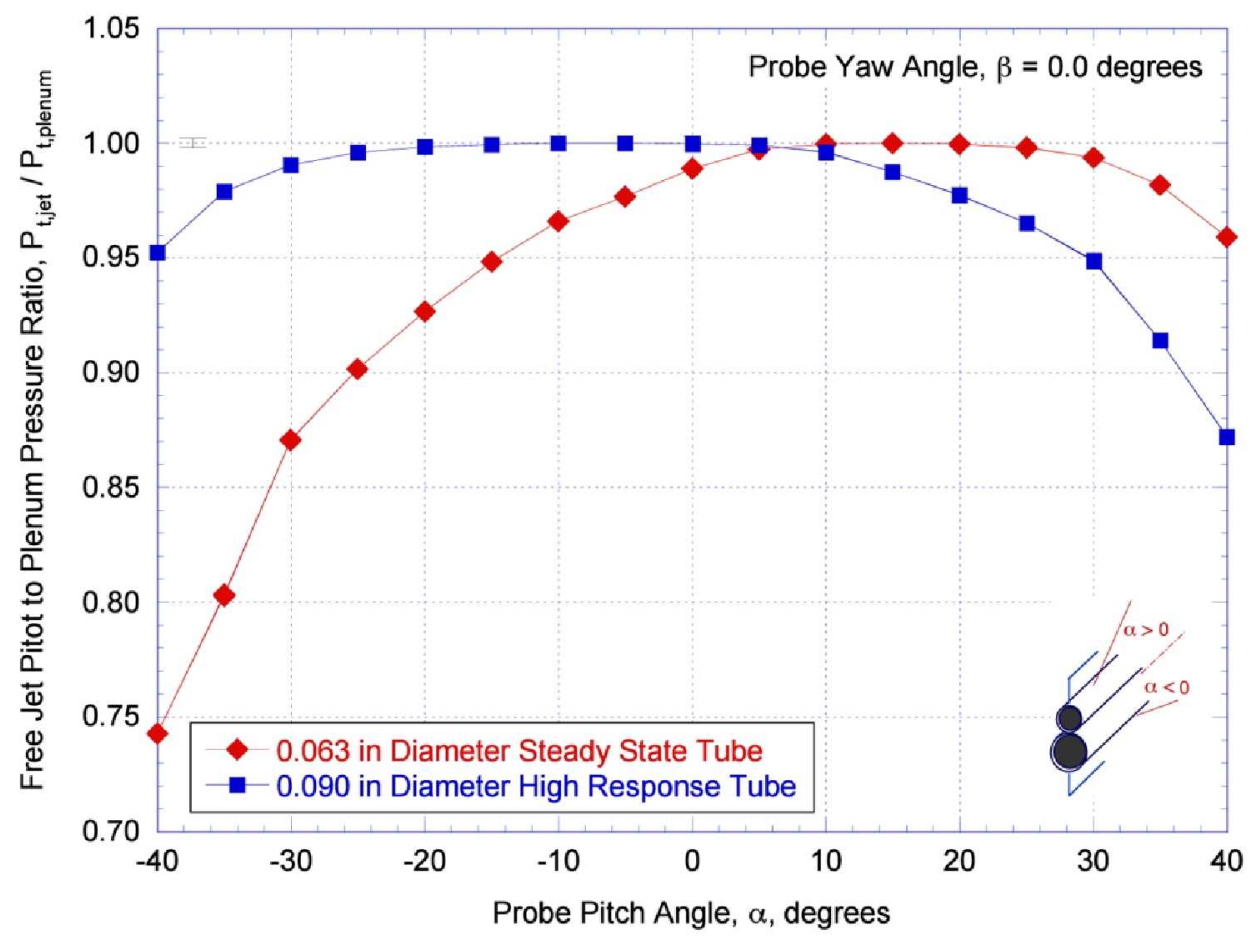

Figure 9.-Effect of Pitch Angle on the Accuracy of Double-Barreled Combination Pitot Pressure Probe Measurements of Stagnation Pressure Ratio at $\mathrm{M}_{\mathrm{jet}}=0.9$.

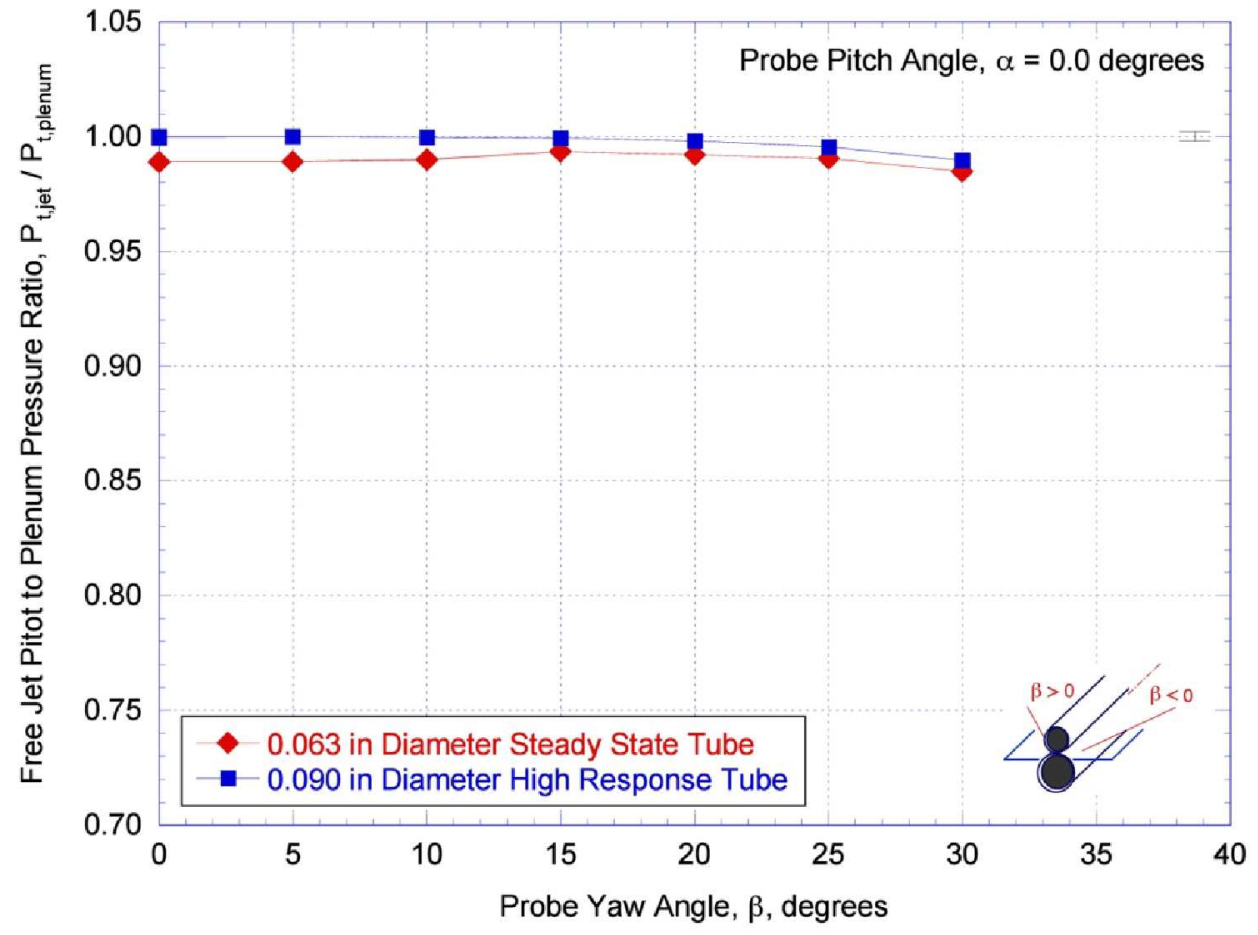

Figure 10.-Effect of Yaw Angle on the Accuracy of Double-Barreled Combination Pitot Pressure Probe Measurements of Stagnation Pressure Ratio at $M_{j e t}=0.9$. 


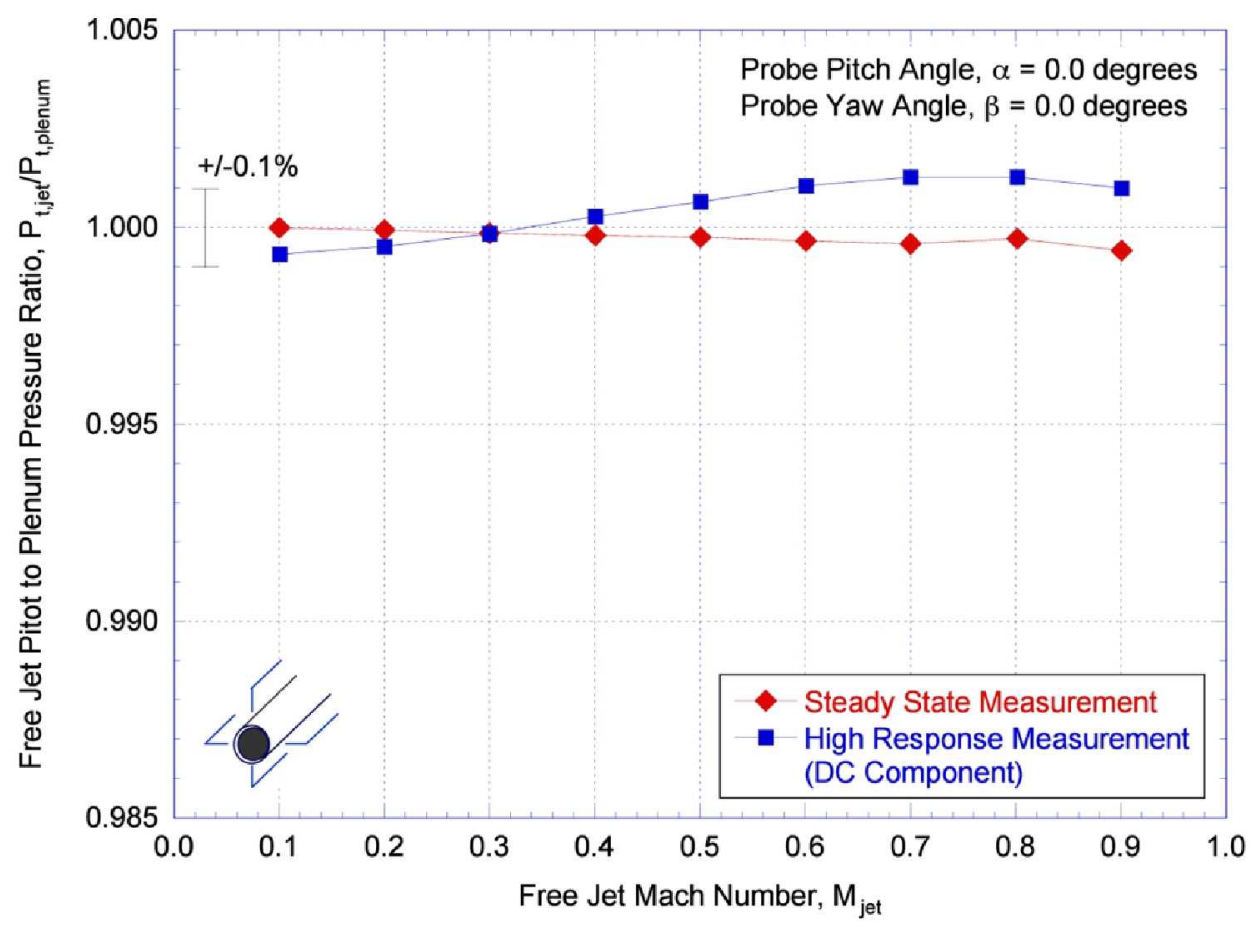

Figure 11.-Effect of Free Jet Mach Number on the Accuracy of Prati Combination Pitot Pressure Probe Measurements of Stagnation Pressure Ratio.

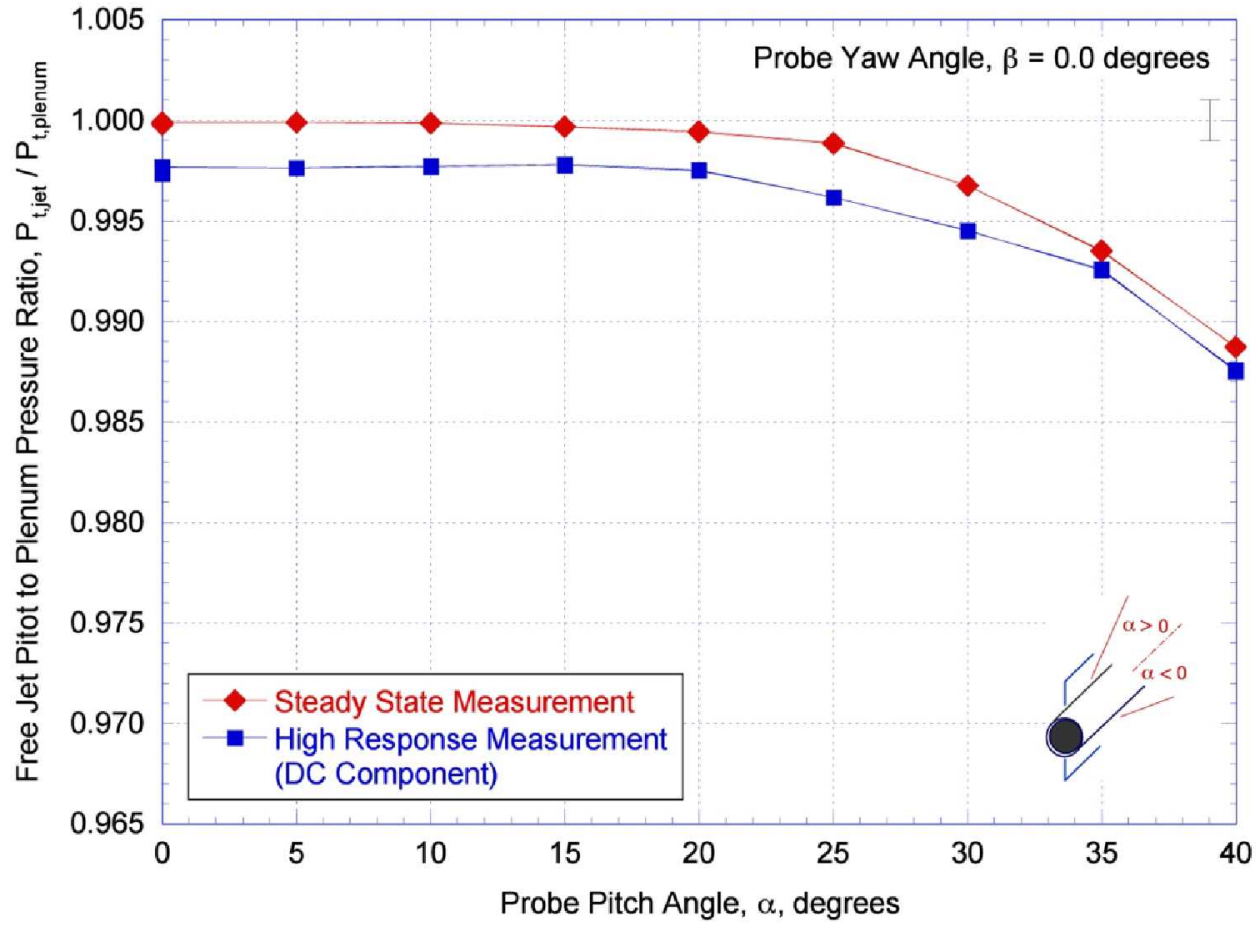

Figure 12.-Effect of Pitch Angle on the Accuracy of Prati Combination Pitot Pressure Probe Measurements of Stagnation Pressure Ratio at $M_{j e t}=0.3$. 


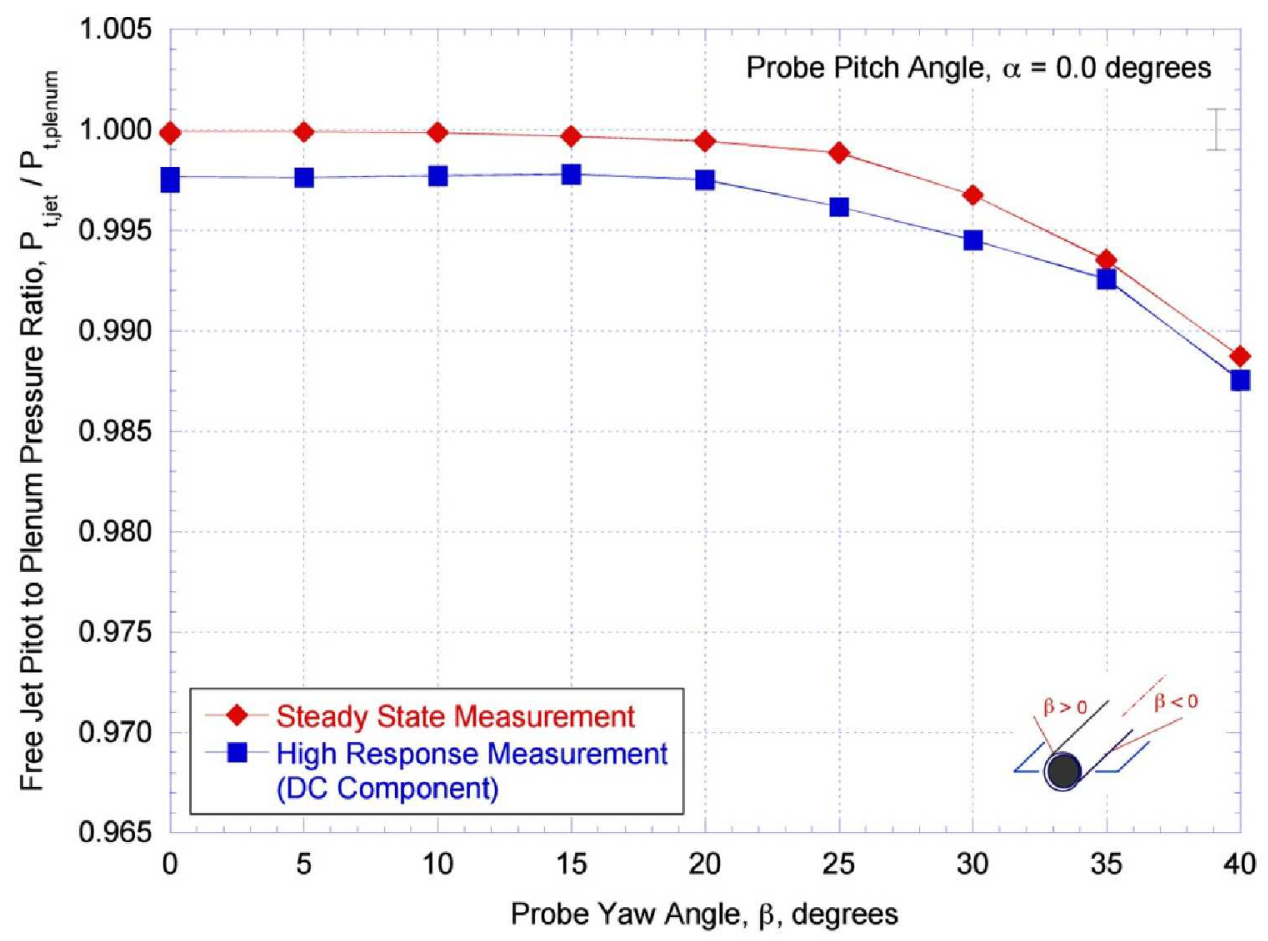

Figure 13.-Effect of Yaw Angle on the Accuracy of Prati Combination Pitot Pressure Probe Measurements of Stagnation Pressure Ratio at $\mathrm{M}_{\mathrm{jet}}=0.3$.

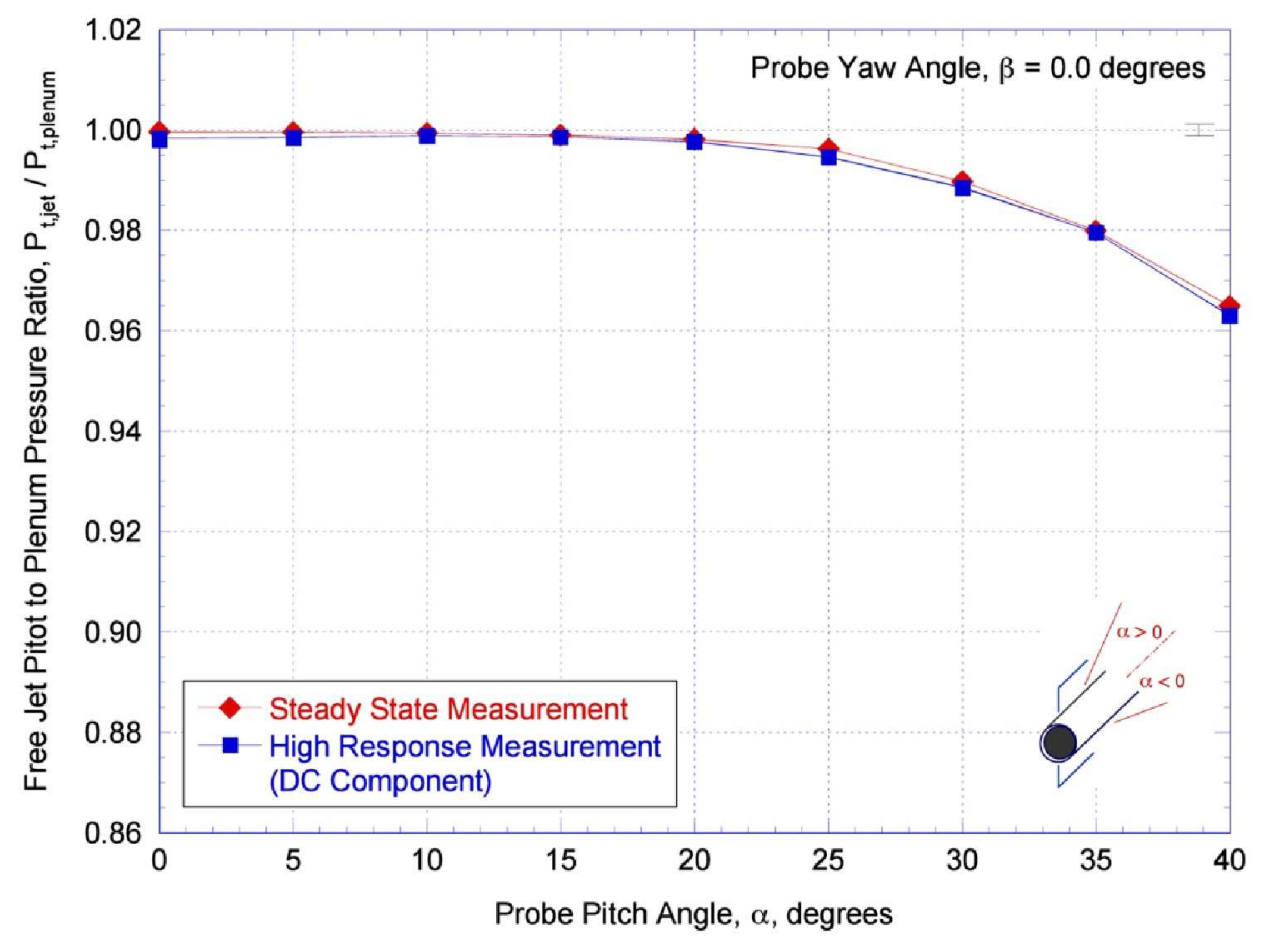

Figure 14.-Effect of Pitch Angle on the Accuracy of Prati Combination Pitot Pressure Probe Measurements of Stagnation Pressure Ratio at $\mathrm{M}_{\mathrm{jet}}=0.6$. 


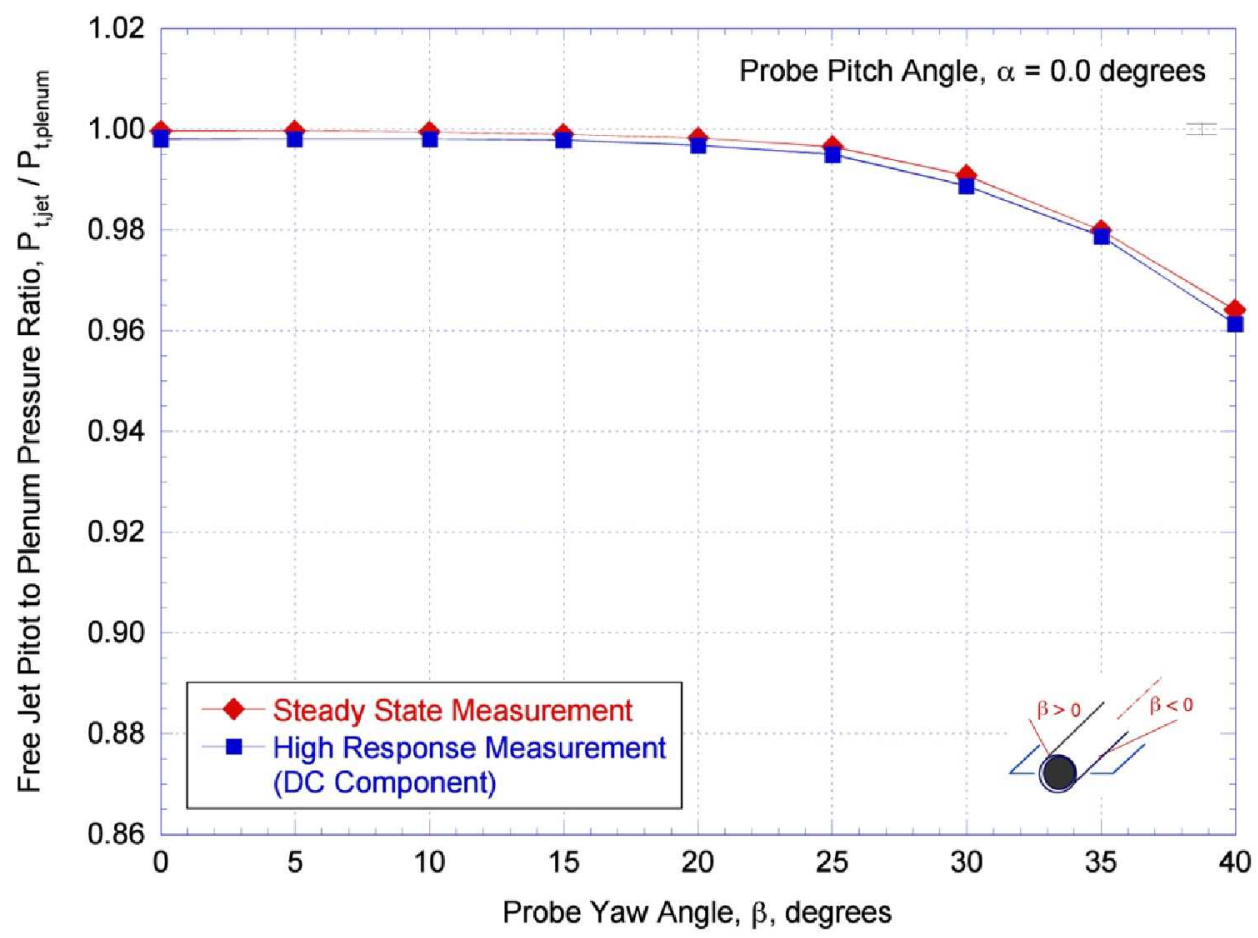

Figure 15.-Effect of Yaw Angle on the Accuracy of Prati Combination Pitot Pressure Probe Measurements of Stagnation Pressure Ratio at $\mathrm{M}_{\mathrm{iet}}=\mathbf{0 . 6}$.

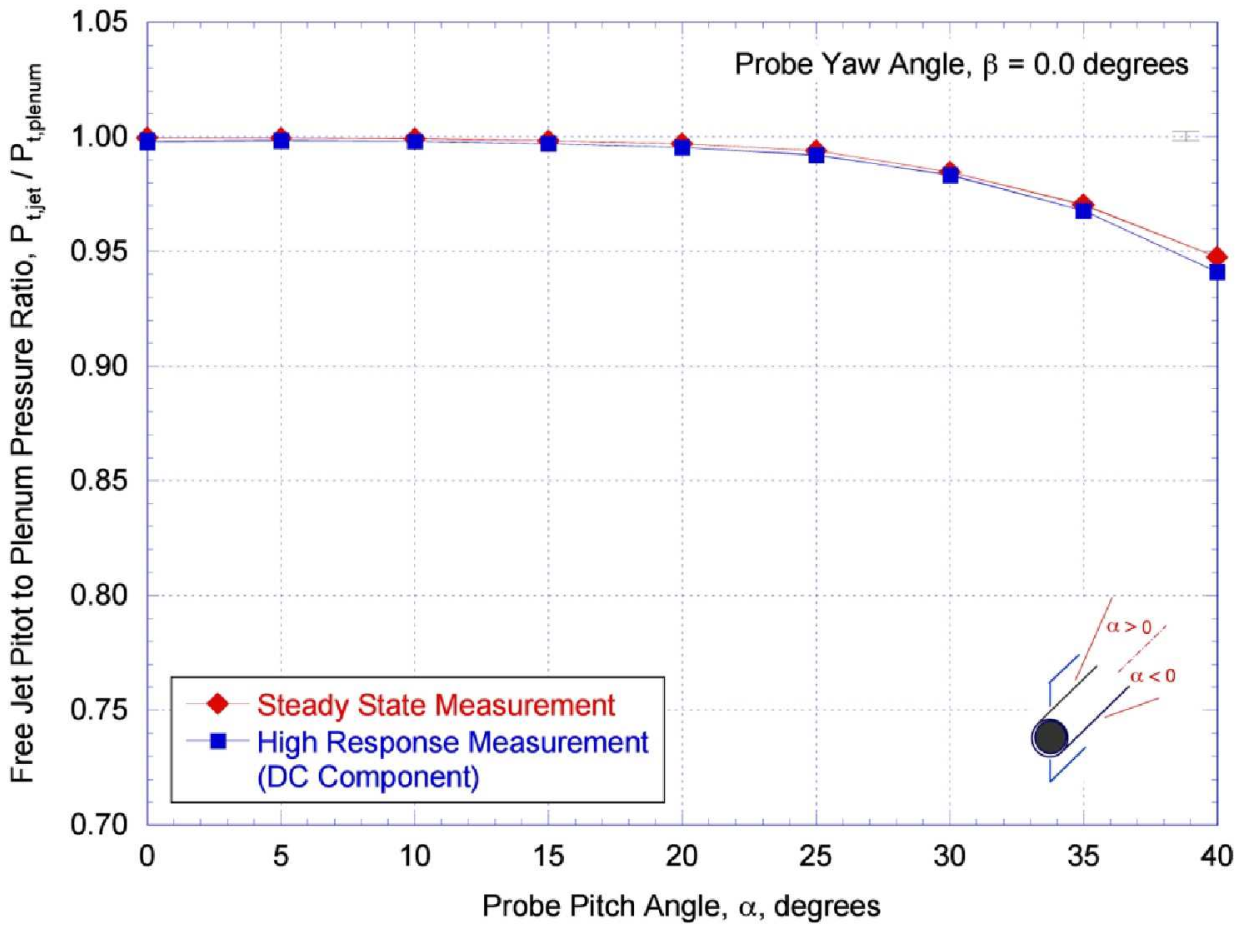

Figure 16.-Effect of Pitch Angle on the Accuracy of Prati Combination Pitot Pressure Probe Measurements of Stagnation Pressure Ratio at $M_{j e t}=0.9$. 


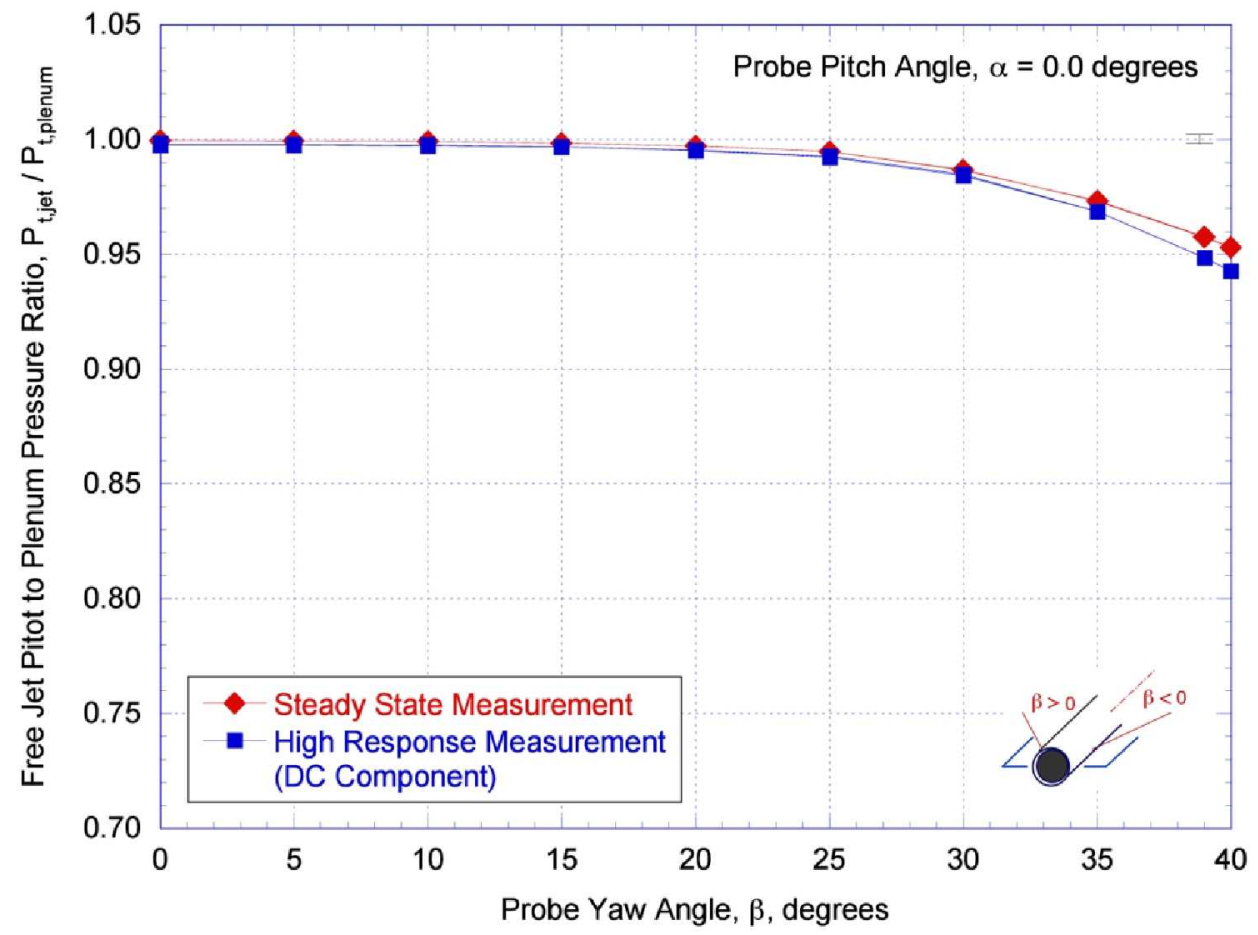

Figure 17.-Effect of Yaw Angle on the Accuracy of Prati Combination Pitot Pressure Probe Measurements of Stagnation Pressure Ratio at $M_{j e t}=0.9$. 


\begin{tabular}{|c|c|c|}
\hline \multicolumn{2}{|c|}{ REPORT DOCUMENTATION PAGE } & $\begin{array}{l}\text { Form Approved } \\
\text { OMB No. 0704-0188 }\end{array}$ \\
\hline \multicolumn{3}{|c|}{ 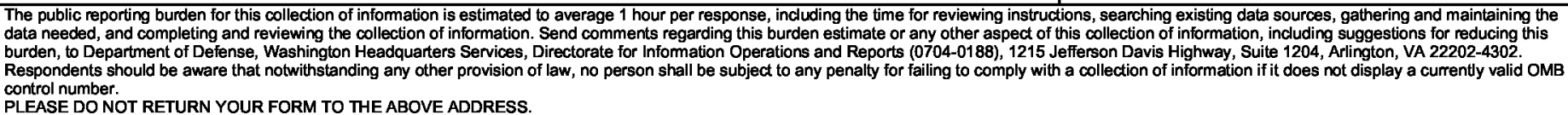 } \\
\hline $\begin{array}{l}\text { 1. REPORT DATE (DD-MM-YYYY) } \\
01-10-2009\end{array}$ & $\begin{array}{l}\text { 2. REPORT TYPE } \\
\text { Technical Memorandum }\end{array}$ & 3. DATES COVERED (From - To) \\
\hline \multirow{3}{*}{\multicolumn{2}{|c|}{$\begin{array}{l}\text { 4. TITLE AND SUBTITLE } \\
\text { An Experimental Evaluation of the Performance of Two Combination Pitot Pressure Probes }\end{array}$}} & 5a. CONTRACT NUMBER \\
\hline & & 5b. GRANT NUMBER \\
\hline & & 5c. PROGRAM ELEMENT NUMBER \\
\hline \multirow{3}{*}{\multicolumn{2}{|c|}{$\begin{array}{l}\text { 6. AUTHOR(S) } \\
\text { Arend, David, J.; Saunders, John, D. }\end{array}$}} & 5d. PROJECT NUMBER \\
\hline & & 5e. TASK NUMBER \\
\hline & & $\begin{array}{l}\text { 5f. WORK UNIT NUMBER } \\
\text { WBS 561581.02.08.03.21.03 }\end{array}$ \\
\hline \multicolumn{2}{|c|}{$\begin{array}{l}\text { 7. PERFORMING ORGANIZATION NAME(S) AND ADDRESS(ES) } \\
\text { National Aeronautics and Space Administration } \\
\text { John H. Glenn Research Center at Lewis Field } \\
\text { Cleveland, Ohio 44135-3191 }\end{array}$} & $\begin{array}{l}\text { 8. PERFORMING ORGANIZATION } \\
\text { REPORT NUMBER } \\
\text { E-16944 }\end{array}$ \\
\hline \multirow{2}{*}{\multicolumn{2}{|c|}{$\begin{array}{l}\text { 9. SPONSORING/MONITORING AGENCY NAME(S) AND ADDRESS(ES) } \\
\text { National Aeronautics and Space Administration } \\
\text { Washington, DC 20546-0001 }\end{array}$}} & $\begin{array}{l}\text { 10. SPONSORING/MONITOR'S } \\
\text { ACRONYM(S) } \\
\text { NASA; AIAA }\end{array}$ \\
\hline & & $\begin{array}{l}\text { 11. SPONSORING/MONITORING } \\
\text { REPORT NUMBER } \\
\text { NASA/TM-2009-215632; AIAA-2009- } \\
1073\end{array}$ \\
\hline \multicolumn{3}{|c|}{$\begin{array}{l}\text { 12. DISTRIBUTION/AVAILABILITY STATEMENT } \\
\text { Unclassified-Unlimited } \\
\text { Subject Categories: } 02,05,07 \text {, and } 35 \\
\text { Available electronically at http://gltrs.grc.nasa.gov } \\
\text { This publication is available from the NASA Center for AeroSpace Information, 443-757-5802 }\end{array}$} \\
\hline
\end{tabular}

\section{SUPPLEMENTARY NOTES}

\section{ABSTRACT}

Experimental tests have been completed which recorded the ability of two combination steady state and high response time varying Pitot probe designs to accurately measure steady stagnation pressure at a single location in a flow field. Tests were conducted of double-barreled and coannular Prati probes in a 3.5 in. diameter free jet probe calibration facility from Mach 0.1 to 0.9 . Geometric symmetry and pitch (-40 to $\left.40^{\circ}\right)$ and yaw $\left(0^{\circ}\right.$ to $\left.40^{\circ}\right)$ angle actuation were used to fully evaluate the probes. These tests revealed that the double-barreled configuration induced error in its steady state measurement at zero incidence that increased consistently with jet Mach number to 1.1 percent at Mach 0.9. For all Mach numbers, the double-barreled probe nulled at a pitch angle of approximately $7.0^{\circ}$ and provided inconsistent measurements when yawed. The double-barreled probe provided adequate measurements via both its steady state and high response tubes (within \pm 0.15 percent accuracy) over unacceptable ranges of biased pitch and inconsistent yaw angles which varied with Mach number. By comparison, the coannular probe provided accurate measurements (at zero incidence) for all jet Mach numbers as well as over a flow angularity range which varied from $\pm 26.0^{\circ}$ at Mach $0.3^{\circ}$ to $\pm 14.0^{\circ}$ at Mach 0.9 . Based on these results, the Prati probe is established as the preferred design. Further experimental tests are recommended to document the frequency response characteristics of the Prati probe. 15. SUBJECT TERMS

Pneumatic probes; Pitot tubes; Pressure measurement; Steady state; Dynamic pressure; Stagnation pressure; Free jets; Wind tunnel tests; Inlet pressure; Compressible flow; Gas dynamics

\begin{tabular}{|c|c|c|c|c|c|}
\hline \multicolumn{3}{|c|}{ 16. SECURITY CLASSIFICATION OF: } & \multirow{2}{*}{$\begin{array}{l}\text { 17. LIMITATION OF } \\
\text { ABSTRACT } \\
\text { UU }\end{array}$} & \multirow{2}{*}{$\begin{array}{l}\text { 18. NUMBER } \\
\text { OF } \\
\text { PAGES } \\
23\end{array}$} & \multirow{2}{*}{$\begin{array}{l}\text { 19a. NAME OF RESPONSIBLE PERSON } \\
\text { STT Help Desk (email:help@sti.nasa.gov) } \\
\text { 19b. TELEPHONE NUMBER (include area code) } \\
\text { 443-757-5802 }\end{array}$} \\
\hline $\begin{array}{l}\text { a. REPORT } \\
\text { U }\end{array}$ & $\begin{array}{l}\text { b. ABSTRACT } \\
\mathrm{U}\end{array}$ & $\begin{array}{l}\text { c. THIS } \\
\text { PAGE } \\
\text { U }\end{array}$ & & & \\
\hline
\end{tabular}



